\title{
Study of fine needle aspiration cytology evaluation of peripheral lymph nodes
}

\author{
Gayen P. ${ }^{1}$, Ghosh S. ${ }^{2 *}$, Naskar S. ${ }^{3}$ \\ DOI: https://doi.org/10.17511/ijmrr.2019.i04.02 \\ 1 Prosenjit Gayen, Assistant Professor, Department of Pathology, Malda Medical College, Malda, West Bengal, India. \\ 2* Saswata Ghosh, Assistant Professor, Department of Chest Medicine, Malda Medical College, Malda, West Bengal, India. \\ 3 Subhrajyoti Naskar, Assistant Professor, Department of Community Medicine, Malda Medical College, Malda, West Bengal, India.
}

Introduction: Lymph nodes are an integral component of the immune system and their enlargement is commonly noted in clinical practice in a wide spectrum of diseases, including infections like tuberculosis and malignancy. FNAC is an important diagnostic tool for rapid evaluation of mainly superficial lesions, especially of lymph nodes. It is cost effective, relatively less traumatic, and enables the pathologist to provide the clinician with a diagnosis in a very short time, and hence is ideal especially for OPD patients. Objectives: 1 . To study the age and sex distribution of the patients of FNAC of peripheral lymph node. 2. To study the spectrum of diseases diagnosed on FNAC of peripheral lymph nodes. Methods: Cross-sectional hospital based Observational study. Total 50 patients who had superficial lymphadenopathy were included in this study. Male patients were 21 $(42 \%)$ and Female patients were 29 (58\%). FNAC was performed on this 50 patients. Diagnosis was made by light Microscopy. Result was tabulated and statistical analysis was done. Results: Male patients were $21(42 \%)$ and Female patients were $29(58 \%) .50 \%$ patients were in the age group of 21 to 40 years. Reactive hyperplasia was $46 \%$ and Granulomatous lymphadenitis was $18 \%$. Cervical lymph nodes were most commonly involved. Conclusion: FNAC is a simple, quick, low cost, minimally invasive and easy diagnostic procedure which is very much helpful in the diagnosis of diseases causing superficial lymphadenopathy in all age groups. Reactive hyperplasia of lymph node was the most common cytological diagnosis followed by Granulomatous lymphadenitis.

Keywords: FNAC, Granulomatous lymphadenitis, Lymph node, Reactive hyperplasia

Corresponding Author

Saswata Ghosh, Assistant Professor, Department of Chest Medicine, Malda Medical College, Malda, West Bengal, India.

Email: drsaswata1969@gmail.com

\section{How to Cite this Article}

Gayen P, Ghosh S, Naskar S. Study of fine needle aspiration cytology evaluation of peripheral lymph nodes. Biomed Rev J Basic Appl Med Sci. 2019;7(4):259-265.

Available From

https://ijmrr.medresearch.in/index.php/ijmrr/article/ view/1067
To Browse

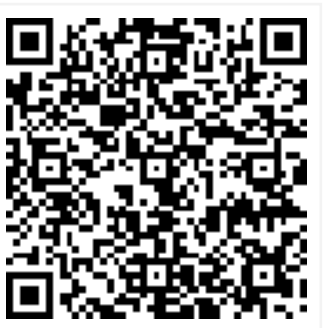

Manuscript Received 2019-05-26

Conflict of Interest No

Review Round 1
2019-06-04
Funding
Nil

Canding (c) 2019 by Prosenjit Gayen, Saswata Ghosh, Subhrajyoti Naskar and Published by Siddharth Health Research and Social
Welfare Society. This is an Open Access article licensed under a Creative Commons Attribution 4.0 International License https://creativecommons.org/licenses/by/4.0/ unported [CC BY 4.0].

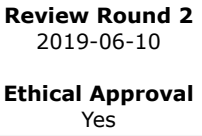

2019-06-14

Note 


\section{Introduction}

Lymph nodes are a site for organized collections of lymphoreticular tissue and are pink gray bean shaped encapsulated organs. They are located at anatomically constant points along the course of lymphatic vessels. The common sites of distribution are cervical, axillary, mediastinal, retroperitoneal, iliac, and inguinal regions. Their enlargement is noted in a wide spectrum of diseases, including infections and malignancy, they are a common finding in clinical practice. Therefore, peripheral lymphadenopathy is common in all age groups and management of cases depends on lymph node pathology, which can be studied by collecting material through fine-needle aspiration or excision biopsy [1].

Fine needle aspiration (FNA) [Fine Needle Aspiration Cytology (FNAC)] technique was first introduced by Greig and Grey [2]. Since the 1960's, it has been used extensively as a diagnostic tool for rapid evaluation of mainly superficial lesions, especially of lymph nodes. It is cost effective, relatively less traumatic, and enables the pathologist to provide the clinician with a diagnosis in a very short time, and hence is ideal especially for OP patients [3].

Lymphadenopathy is one of the most common clinical presentations with variable etiologies and one of the major causes of morbidity [4]. In developing countries, infective lymphadenopathy is quite common, mostly due to high prevalence of tuberculosis. However, still a large percentage of lymphadenopathies in adults turn out to be malignant [5]. The diagnosis of the cause underlying the enlarged lymph node (s) enables the clinician to plan appropriate management for each patient. Enlarged superficial lymph nodes are easily amenable to evaluation by FNA technique and hence FNAC forms an important diagnostic tool in the armamentarium of the pathologist [6].

\section{Objective}

01. To study the age and sex distribution of the patients of FNAC of peripheral lymph node .

02. To study the spectrum of diseases diagnosed on FNAC of peripheral lymph nodes.

\section{Method}

Study Type: Cross-sectional hospital based Observational study.
Sample Size: Total 50 patients with lymphadenopathy who attended for FNAC of superficial lymph nodes in a tertiary centre in West Bengal

Sampling technique: Consecutive non probability technique used, consensus sampling.

Inclusion Criteria: Patients with following criteria who attended pathology department of a tertiary medical centre in West Bengal - Patients having superficial lymphadenopathy, Patients with age between $>6$ months and $<90$ years and Patients with proper consent.

Exclusion Criteria: Uncooperative patients and Inadequate sample

Study Procedure: The study commenced after obtaining permission from Institutional Ethical Committee and written informed consent from patients.

A thorough systemic and local examination of patients was done. Site, size, consistency and relation of enlarged lymph nodes to surrounding structures was noted. Relevant clinical history was recorded.

FNAC was performed using 22-24 gauge needle, 10 $\mathrm{ml}$ syringe and FNAC gun. Some slides were air dried for MGG and ZN stain \& some were alcohol fixed for PAP Stain. Proper staining was done. Stained slides were examined under microscope and reporting was done.

Place of study: Department pathology of a tertiary medical centre in West Bengal

Data analysis: All data gathered were tabulated on a master chart and analyzed using charts, diagrams by a statistical software SPSS version 22 .

Statistical Methods- Percentage Prevalence was calculated using SPSS version 22 software.

\section{Result}

Table-1: Showing distribution of age of FNAC patients of superficial lymph nodes.

\begin{tabular}{|l|l|l|l|}
\hline Serial No & \multicolumn{1}{|c|}{ Age Group } & Number of Patients & Percentage (\%) \\
\hline 1 & $0-10$ years & 4 & 8 \\
\hline 2 & $11-20$ years & 11 & 22 \\
\hline 3 & $21-30$ years & 16 & 32 \\
\hline 4 & $31-40$ years & 9 & 18 \\
\hline 5 & $41-50$ years & 6 & 12 \\
\hline 6 & 51 years and above & 4 & 8 \\
\hline
\end{tabular}


In the present study FNAC was performed in 50 patients who had superficial lymphadenopathy. Table 1 showing distribution of age.

Most of the patients were in the age group of 21 to 30 years followed by the age group of 11 to 20 years. Means $32 \%$ patients were in the age group of 21 to 30 years and $22 \%$ were in the age group of 11 to 20 years (fig 1 ).

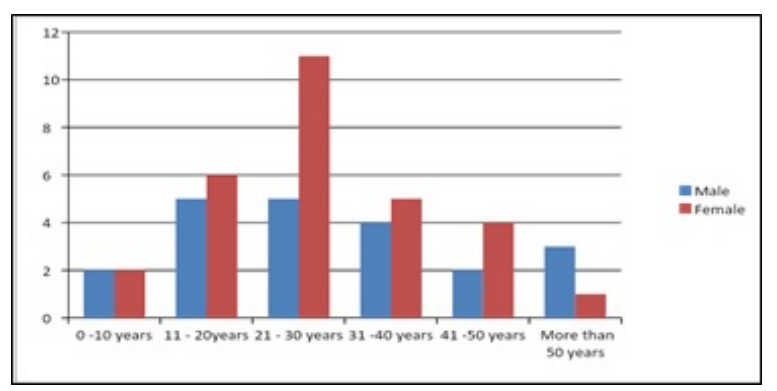

Fig-1: Showing Age and Sex distribution

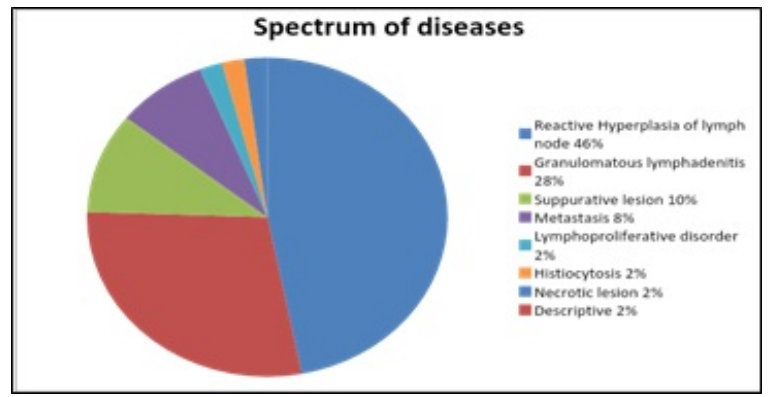

Fig-2: Showing spectrum of Diseases diagnosed in FNAC of superficial lymph nodes.

Table-2: Showing distribution of sex of FNAC patients of superficial lymph nodes.

\begin{tabular}{|l|l|l|l|}
\hline Serial No. & \multicolumn{1}{|c|}{ Sex } & \multicolumn{1}{c|}{ Number of Patients } & Percentage \\
\hline 1 & Male & 21 & $42 \%$ \\
\hline 2 & Female & 29 & $58 \%$ \\
\hline & Male + Female & Total $=50$ & \\
\hline
\end{tabular}

Number of female patients was more than that of male patients (table 2). Number of female patients was 29 and that of male patients was 21 i. e. female patients were $58 \%$ and male patients were $42 \%$ (Fig 1)

Table-3: Showing different cases found in FNAC of lymph node.

\begin{tabular}{|l|l|l|}
\hline Serial No. & \multicolumn{1}{|c|}{ Name of the diseases } & Number of patients \\
\hline 1 & Reactive hyperplasia of lymph node & 23 \\
\hline 2 & Granulomatous lymphadenitis & 14 \\
\hline 3 & Suppurative leasion & 5 \\
\hline 4 & Metastasis & 4 \\
\hline 5 & Lymphoproliferative disorder & 1 \\
\hline
\end{tabular}

\begin{tabular}{|l|l|l|}
\hline 6 & Histiocytosis & 1 \\
\hline 7 & Necrotic lesion & 1 \\
\hline 8 & Descriptive or non-conclusive & 1 \\
\hline
\end{tabular}

Table-4: Showing Prevalence of different cases found in FNAC of lymph node.

\begin{tabular}{|l|l|l|}
\hline Serial No. & \multicolumn{1}{|c|}{ Name of Diseases } & Percentage \\
\hline 1 & Reactive hyperplasia of lymph node & 46 \\
\hline 2 & Granulomatous lymphadenitis & 28 \\
\hline 3 & Suppurative lesion & 10 \\
\hline 4 & Metastasis & 8 \\
\hline 5 & Lymphoproliferative disorder & 2 \\
\hline 6 & Histiocytosis & 2 \\
\hline 7 & Necrotic lesion & 2 \\
\hline 8 & Descriptive or non-conclusive & 2 \\
\hline
\end{tabular}

Diagnosis (Fig 2) was made on findings of light microscopy. Reactive hyperplasia of lymph node was found in 23 cases (46\%) which was highest in number followed by Granulomatous lymphadenitis, number of patients was $14(28 \%)$. Two cases of Granulomatous lymphadenitis were positive for AFB on ZN stained Smears.

Suppurative lesion was $5(10 \%)$ and Metastasis in the lymph node was found in 4 cases (8\%). Lymphoproliferative disorder, Histiocytosis and Necrotic lesion were found in one (2\%) case of each (table 3 \& 4). Non-conclusive (descriptive) result was seen in one case.

Table-5: Showing different sites of FNAC of lymph node

\begin{tabular}{|l|l|l|l|}
\hline Serial No. & \multicolumn{1}{|c|}{ Site of FNAC } & Number of Patients & $(\%)$ \\
\hline 1 & Left cervical lymph node & 14 & $28 \%$ \\
\hline 2 & Right cervical lymph node & 16 & $32 \%$ \\
\hline 3 & Left Submandibular lymph node & 3 & $6 \%$ \\
\hline 4 & Right Submandibular lymph node & 4 & $8 \%$ \\
\hline 5 & Submental lymph node & 2 & $4 \%$ \\
\hline 6 & Left supraclavicular lymph node & 1 & $2 \%$ \\
\hline 7 & Right supraclavicular lymph node & 2 & $4 \%$ \\
\hline 8 & Left inguinal lymph node & 3 & $6 \%$ \\
\hline 8 & Right inguinal lymph node & 2 & $2 \%$ \\
\hline 10 & Axillary lymph node & 3 & $6 \%$ \\
\hline
\end{tabular}

Lymphadenopathy was mostly localised except in two cases of Granulomatous lymphadenitis and one case of Lymphoproliferative disorder. Cervical lymphadenopathy was seen in $30(60 \%)$ cases, submandibular lymphadenopathy in 7 cases, submental lymphadenopathy in 2 caes, supraclavicular lymph node in 3 cases, inguinal lymph node 5 cases and Axillary lymph node 3 cases (table 5). 


\section{Discussion}

In the present study it was observed that most of the patients $(50 \%)$ were in the age group of 11 to 30 years and small number of patients were seen in the age group $0-10$ years $(8 \%) \& 51$ years and above ( $8 \%)$. Similar observation was seen in studies done by Pandit AA et al and Gupta et al. Pandit AA, et al. found $146(51.05 \%)$ patients were in the age group of 0-20years [7]. And Gupta et al also found most of the patients $532(52.26 \%)$ were in the age group of 0-20years [8].

In the present study female (58\%) patients approximately 1.5 times higher than male $(42 \%)$ patients. Duraiswami $R$ et al also found a preponderance of female patients $(61 \%)$ which is similar to the present study [9].

Authors have diagnosed various diseases in the FNAC of different lymph nodes like reactive hyperplasia of lymph node, granulomatous lymphadenitis, Suppurative lesion, metastasis, lymphoproliferative disorder, histiocytosis, necrotic lesion and descriptive or non-conclusive. Among these reactive hyperplasia of lymph node was the most common (46\%) cytological diagnosis in the present study which is comparable to the study done by Duraiswami R et al, Shrivastav $A$ et al, Mohanty $R$ et al and Pandey $P$ et al. Duraiswami R et al found reactive lymph node hyperplasia was the predominant diagnosis in their series $(49.8 \% ; 126$ cases out of 253 FNA evaluations) [9].

Shrivastav A et al observed that in pediatric and adolescents' age group the most common cause of lymphadenopathy was reactive hyperplasia 198 cases out of total 378 cases (52.38\%) [10].

Reactive lymphadenopathy was observed to be the most frequent diagnosis with $122 / 355$ cases (34.36\%) in the study done by Mohanty $\mathrm{R}$ et al [11]. Pandey $P$ et al found that of the 395 patients they studied with palpable lymphadenopathy, among 277 cases of benign lesions, reactive hyperplasia 121 (30.63\%) ranked on top [12]. But tuberculous lymphadenitis $(n=102)$ was found to be the most common pathologic lesion accounting for $47.67 \%$ in the study of Kumar $\mathrm{H}$ et al [13].

In the present study Granulomatous lymphadenitis was the second most common (28\%) cytological diagnosis. Duraiswami R et al found Granulomatous lymphadenitis was the second most common diagnosis (37.15\%; 94 out of 253 FNA evaluations) in their study [9].
The second most frequent diagnosis was observed to be chronic Granulomatous inflammation with $72 / 355$ cases $(20.28 \%)$ in the study done by Mohanty $\mathrm{R}$ et al [11]. But Kumar $\mathrm{H}$ et al found the second most common diagnosis was reactive (nonspecific) lymphadenitis ( $n=95)$ constituting $44.39 \%$ of Cases [13]. Shilpa $G$ et al also found reactive lymph node hyperplasia was the second most common diagnosis [14].

In the present study Suppurative lesion was found in $10 \%(5 / 50)$ of cases. Pandey $\mathrm{P}$ et al found pyogenic lymphadenitis in 43 cases $(10.88 \%)$ which is similar to the present study [12]. Gojiya $\mathrm{P}$ et al found Acute Suppurative lesion in 37/266 (14\%) cases [15]. Shakya $\mathrm{G}$ et al found acute suppurative lesion in $12.4 \%$ cases [16].

In the present study it was observed that in the metastasis in 4 cases out of 50 patients of lymphadenopathy; i. e. Prevalence is $8 \%$. Site of metastasis was - 1 in cervical lymph node, 1 in supraclavicular lymph node, 1 in left axillary lymph node with primary carcinoma in left breast and one in left inguinal lymph node. Sharma R.I. et al found metastatic deposits in lymph node aspirates of 28 cases $(10.4 \%)$ [17].

Bhavani et al found metastatic deposits in $9.5 \%$ of lymph nodes they studied [18]. Their findings are similar to the present study. Patel et al and Ghartimagar et al found slightly higher number of metastatic deposits. They found metastatic deposits in $27.06 \%$ and $18 \%$ of cases respectively $[19,20]$. Various lymph node groups were involved in different types of lymphadenopathy. In the present study it has been found that the most common group of lymph nodes involved in various types of lymphadenopathy was the cervical group of lymph nodes. Authors found in $84 \%$ cases cervical groups lymph nodes were involved. Axillary lymph nodes were less commonly involved. Study of Badge SA et al is similar to the present study. Out of 310 cases, 240 patients were presented with cervical lymphadenopathy in their study [21].

\section{Conclusion}

FNAC is a simple, quick, low cost, minimally invasive and easy diagnostic procedure which is very much helpful in the diagnosis of diseases causing superficial lymphadenopathy.

In the present study authors found FNAC of lymph nodes was helpful in the diagnosis of various diseases with accuracy. 
Benign and malignant diseases were easily diagnosed by this simple diagnostic procedure.

This test can be performed in very young age group to very old individuals in a minimally equipped outdoor setting. In the present study most common age group is 21 to 40 years with predominance of female patients. Reactive hyperplasia of lymph node was the most common diagnosis followed by Granulomatous lymphadenitis.

Limitations- Small numbers of patients were included in the study.

\section{Contribution by Authors}

01. Dr Prasenjit Gayen- Concept designing and conducting the study \& performing and reporting the FNAC.

02. Saswata Ghosh and - Conducting the study and writing the manuscript.

03. Subhrajyoti Naskar- Guiding the study procedure and preparing the manuscript suitable for publication.

Acknowledgement: Mr. Dipak Das, Mr. Rajib Manna, Mr. Manabesh Pramanik and Ms Jaya Ghosh have helped me performing the FNAC, staining and conducting the study.

\section{Reference}

01. Vimal S, Dharwadkar A, Chandanwale SS, Vish wanathan V, Kumar H. Cytomorphological study of lymph node lesions- A study of 187 cases. Med J Dr DY Patil University. 2016;9(1)43-50.

DOI: $10.4103 / 0975-2870.172428$ [Crossref]

02. Malaker D, Jajoo ILN, Swarup K, Gupta OP, Jain AP, Poflee VW. A clinical evaluation of fine Needle aspiration cytology in the diagnosis of lymphadenopathy. Ind J Tub. 1991;17-9.

[Crossref]

03. Shah PC, Patel CB, Bhagat V, Modi H. Evaluation of peripheral lymphadenopathy by fine needle aspiration cytology; a one year study at a tertiary centre. Int $\mathrm{J}$ Res Med Sci. 2016;4(1)120-5.

DOI: $10.18203 / 2320-6012 . i j r m s 20160016$ [Crossref]

04. Chawla N, Nandini NM. FNAC in lymph node disorders a hospital study in Southern India. J Cytol. 2007;24(2)105-7.

[Crossref]
05. Qadri SK, Hamdani NH, Shah P, Lone MI, Baba KM. Profile of lymphadenopathy in Kashmir valley- a cytological study. Asian Pac J Cancer Prev. 2012;13(8)3621-5.

DOI: 10.7314/apjcp.2012.13.8.3621 [Crossref]

06. Wilkinson AR, Mahore SD, Maimoon SA. FNAC in the diagnosis of lymph node malignancies- $A$ simple and sensitive tool. Indian J Med Paediatr Oncol. 2012;33(1)21-4.

DOI: $10.4103 / 0971-5851.96964$ [Crossref]

07. Pandit AA, Candes FP, Khubchandani SR. Fine needle aspiration cytology of lymph nodes. J Postgrad Med. 1987;33(3)134-6.

[Crossref]

08. Gupta RK, Naran S, Lallu S, Fauck R. The diagnostic value of fine needle aspiration cytology (FNAC) in the assessment of palpable supraclavicular lymph nodes- a study of 218 cases. Cytopathology. 2003;14(4)201-7.

DOI: $10.1046 / j .1365-2303.2003 .00057 . x$ [Crossref]

09. Duraiswami R, Margam S, Chandran P, Prakash A. Spectrum of pathologies on FNAC evaluation of peripheral lymph nodes at a tertiary care center in hyderabad- a retrospective study. Int J Adv Med. 2017;4(1)27-33.

DOI: $10.18203 / 2349-3933 . i j a m 20164703$ [Crossref]

10. Shrivastav A, Shah HA, Agarwal NM, Santwani PM, Srivastava G. Evaluation of peripheral lymphadenopathy by fine needle aspiration cytology- A three year study at tertiary center. Journal of Dr NTR University of Health Sciences. 2014;3(2)86-91.

DOI: $\quad 10.4103 / 2277-8632.134834$ [Crossref]

11. Mohanty $R$, Wilkinson $A$. Utility of fine needle aspiration cytology of lymph nodes. IOSR J Dent Med Sci. 2013;8(5)13-8.

[Crossref]

12. Pandey $P$, Dixit A, Mahajan NC. The diagnostic value of FNAC in assessment of superficial palpable lymph nodes- a study of 395 cases. Al Ameen J Med Sci. 2013;6(4)320-7.

[Crossref] 
13. Kumar H, Chandanwale SS, Gore CR, Buch AC, Satav VH, Pagaro PM. Role of fine needle aspiration cytology in assessment of cervical lymphadenopathy. Med J Dr DY Patil University. 2013;6(4)400-4.

DOI: $\quad 10.4103 / 0975-2870.118287$ [Crossref]

14. Shilpa G, Nataraju G. Pattern of lymph node diseases in a tertiary level referral center- a cytological study of 943 cases. Inter Biol Med Res. 2013;4(3)3448-52.

[Crossref]

15. Gojiya P, Goswami A, Shah S. Evaluation of Fine Needle Aspiration Cytology of Cervical Lymphadenopathies at Tertiary Care Center. Annals of Patho and Lab Med. 2018;5(1)22-27. [Crossref]

16. Shakya G, Malla S, Shakya KN, Shrestha R. A study of FNAC of cervical lymph nodes. J Nepal Health Res Counc. 2009;7(1)1-5.

DOI: $10.3126 /$ jnhrc.v7i1.2267 [Crossref]

17. Sharma RI, Dharaiya CM. Study of fine needle aspiration cytology of lymphadenopathy in tertiary care centre of Ahmedabad, Gujarat. Trop J Path Micro. 2018;4(3)258-264.

DOI: $10.17511 /$ jopm.2018.i3.04 [Crossref]
18. Bhavani C, Neeraja M, Varalakshmi KP, Ramana Babu PV, Chaitanya B, Sravani P. Role of FNAC in the diagnosis of cervical lymphadenopathy. Int J Med Res Rev. 2014;2;599-603.

DOI: $\quad 10.17511 /$ ijmrr.2014.i06.015 [Crossref]

19. Patel MM, Italiya SL, Dhandha ZB, Dudhat RB, Kaptan KR, Shah MB, et al. Study of metastasis in lymphnodes in FNAC- Our institutional experience. Int J Res Med Sci. 2013;1;451-4. DOI: $10.5455 / 2320-6012 . I j r m s 20131128$ [Crossref]

20. Ghartimagar D, Ghosh A, Ranabhat S, Shrestha MK, Narasimhan R, Talwar OP. Utility of fine needle aspiration cytology in metastatic lymph nodes. J Pathol Nepal. 2011;1;92-5.

[Crossref]

21. Badge SA, Ovhal AG, Azad K, Meshram AT. Study of fine-needle aspiration cytology of lymph node in rural area of Bastar District, Chhattisgarh. Med J DY Patil Univ. 2017;10(2)143-8.

DOI: $10.4103 / 0975-2870.202097$ [Crossref] 